now possible to estimate the dose given and also its distribution in two planes. The histological work on the response of malignant tumours to irradiation, carried out at the Strangeways Research Laboratory, Cambridge, by Dr. F. G. Spear and Dr. A. Glücksmann, is described by these authors in Part 2 of the report and illustrated with photomicrographs. Important conclusions of the report are that the wavelength of the radiation per se had no significant effect on the clinical results, that there was no evidence that cancer of the primary site yielded more readily to radiation than did cancer of the glands, and that increase in the proportion of differentiating cells distinguishes epitheliomata responding favourably to radiation from those that failed to respond. The section of the report dealing with the future of research in radiotherapy contains valuable observations on the comparative value of radium beam therapy, high-voltage $\mathrm{X}$-ray therapy and therapy with electron and neutron beams. To this section, Dr. L. H. Gray contributes a valuable article on the use of radioactive isotopes.

\section{Termites and Building in the Tropics}

AMONG the recommendations of the Commonwealth Entomological Conference in 1948 was that a simple manual should be prepared, designed for the practical builder and dealing with the protection of buildings and building material from termites. The Building Research Station and the Forest Products Research Laboratory, both of the Department of Scientific and Industrial Research, were asked to undertake the preparation of such a manual, and as a result "The Protection of Buildings and Timker against Termites" has now been published (Forest Products Research Bulletin No. 24 ; pp. $41+9$ plates ; H.M. Stationery Office, $1950 ; 1 s .9 d$. net). It is written by W. D. MacGregor, formerly conservator of forests, Nigeria and Sierra Leone, in collaboration with R. C. Fisher, officer in charge of the Entomology Section of the Forest Products Research Laboratory, and should prove of great value to all architects and builders who are concerned in the erection of buildings in countries subject to termite attack. A simple account of the biology and ecological classification of termites is followed by detailed instructions on prevention and control. The greatest emphasis is placed on preventive methods : the use of resistant timbers (indigenous timbers reputed to be resistant to termite attack are listed in an appendix), the impregnation of non-resistant timbers with preservatives, methods of building construction, termite barriers and the like which will prevent access by termites, and notes on the maintenance of such protective structures. The economic losses sustained from the attacks of termites are enormous; the widespread adoption of the methods set out in this manual should go far towards preventing that serious wastage.

\section{Aids to Science Teaching}

ON behalf of Unesco the Ministry of Education has issued another volume in the series "Inventories of Apparatus and Material for Teaching Science". The series has been designed particularly to aid educationists in war-damaged and under-developed countries and takes the form of reference manuals from which the essential equipment necessary to teach science at the various levels may be selected. The lists are based on material not in use in the more highly developed countries. Each manual gives details of the modern curriculum to which the equipment it lists is related. Teachers are therefore given guidance about the kind of course they could undertake and also what equipment would be needed for administrative and experimental purposes. The first volume dealt with the teaching of science in primary, secondary and vocational schools, and the present one with the universities. It covers the subjects of botany, chemistry, geology, physics and zoology and also includes appendixes concerned with common abbreviations and conversion factors used in science, as well as a short list of suppliers of scientific instruments. Copies of the Inventory may be obtained from H.M. Stationery Office, price 12s. 3d.

\section{British Hat and Allied Felt Makers Research Associa- tion : Annual Report}

THE third annual report of the director of research of the British Hat and Allied Felt Makers Research Association, covering the year ended August 1950 (pp. 16; Manchester, 1951), records some progress in research, but at the same time directs attention to the fact that comparatively few firms seem to make regular use of the services the Association can offer in dealing with their day-to-day problems or in the provision of technical and scientific information. The fundamental research programme has continued largely on the same lines as in previous years. The particular groups of the keratin molecule which take part in the carrotting of fur have now been determined with some certainty, and evidence has been obtained on the mode of action between fur and mercuric nitrate/nitric acid carrotting solutions. From extensive measurements of the elastic and other properties of wool and fur felt, a scheme of quality assessment has been drawn up which not only gives a quantitative measure of the material properties but also provides a fibre factor which defines the condition of the individual fibres. This fibre factor can indicate differences in original raw materials or degradation or damage in processing. A study of the felting property of wool noils showed that, for any particular type and treatment of wool, there is a maximum degree of felting and that further treatment of the wool only results in a change in shape. On the technological side, methods of addition and the amounts of acid used in processing fur hoods have been reviewed, the damage to animal fibres in dyeing and other processes examined, and a survey of felting machinery begun.

\section{St. Andrews University Chemical Society}

THE Journal of the St. Andrews University Chemical Society for April 1951 (1, No. 5) contains a number of interesting short papers and provides abundant evidence that the Society is in a flourishing state. D. M. Dunlop describes an Arabic manuscript on alchemy in the University Library, Prof. John Read lectures on historical chemistry as an instrument of culture, Prof. R. D. Haworth on cycloheptane derivatives, and Prof. D. H. Hey on aromatic substitution. Other papers deal with various aspects of chemistry by experts in the fields concerned. The officers of the Society have been fortunate in having available a gift of paper, and they have made good use of it in producing a very attractive record of the lectures given to the Society.

\section{Maritime Meteorology : Conference in Genoa}

THE Geophysical Institute of the University of Genoa is organizing a meeting on maritime meteorology, to be held in Genoa during September 20-22, 